\title{
DESAFIOS DA DIVERSIDADE EM \\ SALA DE AULA: UM ESTUDO SOBRE \\ PERFORMANCES NARRATIVAS \\ DE CRIANÇAS IMIGRANTES
}

Luciana Hartmann ${ }^{I}$

RESUMO: Este artigo procura refletir sobre performances narrativas produzidas por crianças imigrantes em um contexto escolar marcado por intensa diversidade cultural. A análise foi fundamentada nos dados obtidos por meio da pesquisa etnográfico-propositiva intitulada Pequenos Narradores, realizada entre os anos de 2014 e 2015, em duas escolas públicas de ensino fundamental de Paris, França, nas chamadas CLIN - classes de iniciação do francês para crianças não francófonas. Como estratégia metodológica, foram realizadas diversas atividades lúdicas no sentido de favorecer a produção narrativa na sala de aula. A agência das crianças na escolha do que e como contar foi analisada sob a perspectiva dos estudos da performance. Constatou-se que, nesse contexto, as performances narrativas constituem um elemento importante não apenas na traduçáo e organização das experiências dessas crianças imigrantes, mas, sobretudo, na criação e transformação dessas experiências diante da realidade de vida no novo país.

Palavras-chave: Performances narrativas. Imigração. Escola. Criança. Diversidade.

${ }^{1}$ Universidade de Brasília, Departamento de Artes Cênicas - Brasília (DF), Brasil. E-mail: luhartm71@gmail.com

DOI: $10.1590 / C C 0101-32622017168668$ 


\title{
The challenges of diversity in the classroom: a study on narrative performances of immigrant children
}

\begin{abstract}
This article intends to reflect on narrative performances produced by immigrant children in a school environment marked by intense cultural diversity. The analysis is grounded on data obtained through the ethnographicpropositional research entitled "Little Storytellers" held between 2014 and 2015 in two public elementary schools in Paris, France, in the CLIN (a special class to France newcomers). As methodology, several ludic activities were conducted to promote narrative production in the classroom. The agency of children in choosing what and how to tell was analyzed from the perspective of performance studies. We found that, in this context, narrative performances are an important part not only in the translation and organization of the experiences of these immigrant children, but especially in the creation and transformation of these experiences in the new country.
\end{abstract}

Keywords: Narrative performances. Immigration. School. Child. Diversity.

L'histoire de... tinha uma menina ibai busca lenha na mato e olha un lubu. depuche i courri, chora chora, depuche menina mouri. Papa de menina, olha si filha i dita na chon. Papa chora depuche lubu bin i fala keku na chora i cume papa de filha. Depouche mama filha vem i lubu cume mama de menina. Depois lubu i fala: cumacunome: Ratafia.

(Demba e Adul $^{1}$ - 8 e 10 anos - Guiné Bissau)

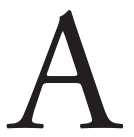

narrativa que serve de epígrafe a este artigo é um pequeno enigma que tem me acompanhado nos últimos anos. Nesse momento, ainda que não o tenha inteiramente solucionado, já disponho de pistas que podem auxiliar a desvendá-lo, possibilitando uma melhor compreensão dos desafios enfrentados pelas crianças imi- 
grantes na escola. Essas pistas foram encontradas por meio da análise de suas performances narrativas.

Antes de mergulhar no pequeno conto de Demba e Adul, acredito que seja importante situar minha trajetória de pesquisa. Tenho trabalhado há cerca de 20 anos na interface entre o teatro e a antropologia. Ao longo desse caminho, a performance tem se mostrado não apenas uma profícua abordagem metodológica, como também uma ferramenta analítica operativa para abordar as expressóes narrativas de diferentes grupos sociais. As tradiçóes teóricas às quais me filio, consequentemente, são aquelas que contribuem na reflexão sobre a riqueza de elementos existentes entre o gesto e a palavra, a voz e o silêncio, a memória e o esquecimento, a tradição e a transformaçáo, a individualidade autoral e a coletividade criadora. Dessa forma, minha dedicação aos estudos da performance vem se baseando nos processos de aprendizagem, transmissão e criação de narrativas (biográficas, ficcionais, tradicionais, entre outras), compreendendo-as como parte de complexos eventos de comunicação, de entretenimento, de criação estética e de construção de conhecimento.

Embora fortemente disseminados e acolhidos, sobretudo, nas artes, na antropologia e na literatura oral, no Brasil apenas recentemente os estudos da performance passaram a dialogar de forma mais direta com a educação e, mais especificamente, com a pedagogia do teatro, campo em que atuo. Como debato em artigo recente (HARTMANN, 2014), a implementação desse novo cruzamento de perspectivas analíticas traz contribuiçôes no sentido de enfatizar o papel dos sujeitos no contexto educacional, a importância que seus corpos, vozes, gestos, experiências, identidades étnicas, de gênero, raça e classe têm nos processos de construção de conhecimento, tanto formais quanto não formais.

Como aponta Icle (2013, p. 20), conjugando de forma dinâmica as dimensôes do ser e do fazer e enfatizando o caráter criativo das relaçôes humanas, a performance permite que a própria prática educativa seja pensada como invençáo. É nesse sentido que as narrativas das crianças imigrantes foram abordadas: como resultantes de uma prática educativa inventada, negociada, provisória, posto que é constantemente transformada. 
Adotando como referência a relação entre os estudos da performance e a educação, portanto, este artigo pretende refletir sobre o poder das performances narrativas de crianças imigrantes não apenas na tradução e organização de suas experiências escolares de contato com a alteridade e com a diversidade, mas, sobretudo, na criação e transformação dessas experiências diante da realidade da vida no novo país.

Nessa perspectiva, a obra do encenador/professor/performer Richard Schechner tem sido uma importante inspiração teórica para minha pesquisa. Um dos principais responsáveis pela criação do campo dos estudos da performance nos Estados Unidos, Schechner (1988) vem desenvolvendo importantes reflexóes sobre o ritual, o jogo, o teatro e as manifestaçóes expressivas no sentido amplo nas mais diferentes sociedades e culturas. $\mathrm{O}$ autor tem colaborado para enriquecer e ampliar o espectro de abordagens dos processos de ensino-aprendizagem e de construção de saberes. Nas palavras dele:

Performance não trata sobre saber de uma vez por todas o que é isso tudo. Performance é, por definição e por prática, provisória, em construção, processual, lúdica: da segunda a enésima vez. Não existe o original, nada como uma fonte que pode ser buscada, encontrada (SCHECHNER, 2010, p. 34, grifo do autor).

Para retomar a narrativa de Demba e Adul, é preciso conhecer o cenário da pesquisa: os meninos a contaram no âmbito do projeto intitulado Petits conteurs ou échangeons nos histoires (Pequenos Contadores ou Troquemos nossas Histórias), que realizei como parte de minha pesquisa de pós-doutorado ${ }^{2}$ em duas escolas públicas francesas de ensino fundamental. O projeto foi desenvolvido nas chamadas CLIN - classe de iniciação do francês para crianças não francófonas (em francês, Classe d'initiation pour non-francophones $)^{3}$.

As CLIN são turmas especiais que acolhem crianças entre 6 e 12 anos. Atualmente, existem cerca de 50 dessas classes de iniciação em escolas parisienses, contabilizando aproximadamente 850 alunos $^{4}$. A ideia de ensinar a língua francesa a jovens imigrantes, a fim de "pro- 
mover seu acolhimento e integração", conforme consta de diversos documentos oficiais do Ministério francês de Educação ${ }^{5}$, remonta pelo menos 50 anos, coincidindo com a independência de colônias francesas e com o início do afluxo de grandes contingentes de imigrantes ao país. No entanto, desde a proclamação da obrigatoriedade da educação na França, com a lei de 28 de março de 1882, a escola já tinha por missão integrar à comunidade nacional todas as crianças francesas, compreendidas aí os jovens do meio rural não francófono e os estrangeiros (MESMIN, 1995, p. 12).

Embora a circular que oficializa a implementação das CLIN nas escolas francesas date de $1970^{6}$, a primeira CLIN foi aberta em 1965, e em 1968 já se podiam contabilizar 39 classes de iniciação em funcionamento na França (GAUTIER, 2006). Essa circular prevê que todas as crianças recém-chegadas passem por um período de adaptação na CLIN, que poderá variar de alguns meses até um ano (ou mais, em casos específicos), dependendo das demandas de aprendizagem. O número de horas durante as quais a criança frequentará a CLIN também dependerá da avaliação feita pela equipe pedagógica, mas o mínimo previsto é de 12 horas por semana de estudo da língua francesa (VASSEUR, 2003). A meta é integrar a criança pouco a pouco na classe ordinária, correspondente, em geral, à sua faixa etária. Esse processo de integração está pautado na ideia de que a integração parcial favoriza as trocas linguísticas com outros alunos francófonos, contribuindo para a aquisição da linguagem e da cultura (entenda-se cultura escolar com suas regras e normas, mas também cultura francesa em sentido amplo). O boletim oficial de educação nacional n. ${ }^{\circ} 10$, de 25 de abril de 2002, explicita esse aspecto:

Se o domínio da língua francesa nos seus usos orais e escritos é uma prioridade, a aprendizagem de viver juntos constitui uma outra finalidade essencial da escola. Assim, a integração ao meio ordinário constitui não somente um princípio ou um objetivo, mas também a modalidade principal da escolarização (tradução nossa) ${ }^{7}$. 
Uma CLIN deve receber, no máximo, 15 alunos ao mesmo tempo, mas essa quantidade varia bastante, de acordo com o número de crianças que chegam (o que ocorre ao longo de todo o ano escolar) e de crianças que vão sendo integradas. Como o fluxo de alunos matriculados na CLIN é imprevisível e possui características muito distintas, a escolarização desse público exige uma organização pedagógica bastante maleável.

Percebi essa diversidade e imprevisibilidade que caracterizam a CLIN assim que comecei minha pesquisa, em fevereiro de 2014, na École Keller, que está localizada no $11 .^{\circ}$ arrondissement de Paris, um bairro conhecido por acolher trabalhadores imigrantes de diversos países. Na turma, naquele primeiro momento, havia 13 crianças, originárias dos seguintes países: Chade (1), Senegal (2), Guiné-Bissau (3), Marrocos (2), Romênia (1), Portugal (1), Colômbia (1), Bangladesh (1) e Brasil (1). Nos meses em que a pesquisa se desenvolveu, chegaram mais dois alunos da República do Congo, dois da China e um dos Estados Unidos. Já na CLIN da École Eugène Varlin (10. ${ }^{\circ}$ arrondissement), onde realizei a segunda fase da pesquisa, havia, em setembro de 2014, seis alunos, originários da Espanha (1), da Mauritânia (1), da Moldávia (1), do Brasil (1), da Gâmbia (1) e da Argélia (1). Posteriormente chegaram mais quatro crianças, duas do Senegal, uma da Romênia e uma da Espanha. Como nos lembra Claude Mesmin em seu livro Psychothérapie des enfants de migrants:

A escola reúne indivíduos que são separados de seu mundo, de seu meio, para lhes colocar juntos e lhes aglutinar de maneiras arbitrárias - simplesmente porque eles habitam o mesmo bairro, por exemplo embora eles não sejam ligados entre si pelas mesmas ligaçôes culturais e sociais (MESMIN, 1995, p. 16, tradução nossa) ${ }^{8}$.

Nessa concepção, a escola se insere como uma importante "zona de contato", no sentido atribuído por Mary Louise Pratt (apud HALL, 2003, p. 31), pois envolve "a copresença espacial e temporal dos sujeitos anteriormente isolados por disjunturas geográficas e históricas 
[...] cujas trajetórias agora se cruzam". Podemos, então, nos perguntar: como as crianças provenientes de diferentes origens étnicas, religiosas e socioculturais dialogam nessa zona de contato específica que são as CLIN? O que elas contam e como compartilham suas histórias?

$\mathrm{Na}$ tentativa de responder a essas perguntas, parti de minha experiência teórico-prática com estudos da performance para propor à professora Noelle Ebel, que atuava na CLIN da École Keller, a realização de uma pesquisa que seria, por um lado, etnográfica, pois previa a observação do cotidiano da turma e, por outro lado, propositiva, pois propunha minha ação direta no sentido de gerar um ambiente favorável à manifestação expressiva das crianças e à escuta de sua produção narrativa. A professora Noelle foi uma parceira importante, porque não somente me propiciou liberdade de ação, como também contribuiu de forma ativa no andamento do processo.

Inicialmente planejamos minha atuação em dez sessões de 1,5 hora por semana. Em poucas semanas, no entanto, em função da boa acolhida da proposta por parte das crianças, esse planejamento foi alterado, e as sessôes foram ampliadas tanto em termos da duração de minha permanência na escola quanto na quantidade de semanas. Como resultado, acompanhei a turma desde o início de fevereiro até o fim do ano letivo, em julho de $2014^{9}$.

Partindo do entendimento de que as crianças são "sujeitos autônomos" (MONTANDON; LONGCHAMP, 2007), capazes de atuar não apenas como interlocutoras em pesquisas antropológicas, mas também como pesquisadoras e coprodutoras de dados e de reflexóes (BEGNAMI, 2010; ALDERSON, 2005), comecei o projeto convidando os estudantes da CLIN a serem, assim como eu, pesquisadores. Expliquei quem eu era, o que eu fazia, minha origem e dei a cada um deles pequenos cadernos para que pudessem escrever, anotar, desenhar, copiar ou inventar as histórias que desejassem ${ }^{10}$. O fato de incitar a participação das crianças como pesquisadoras, portanto, não foi gratuito, pois parto da premissa de que as crianças são "produtoras de cultura" (COHN, 2005) e, nas interações comunicativas com os pares e com os adultos, estão não apenas refletindo, mas também constituindo modos de vida e de relacionamento (SARMENTO, 2003). É importante ainda 
ressaltar que, durante o processo, as crianças, além de elegerem o conteúdo e a forma de suas narrativas, também operavam os equipamentos de registro em áudio e vídeo.

Como foi colocado, compreendo a operatividade da performance tanto no âmbito metodológico quanto no teórico-analítico. Procurando favorecer a produção narrativa, portanto, em um primeiro momento a performance foi adotada como estratégia metodológica, sendo as sessóes de trabalho organizadas da seguinte maneira: iniciava-se com um jogo ou brincadeira envolvendo corporal e vocalmente todo o grupo (incluindo a mim e a professora), depois eu contava uma história, e, numa relação de troca, abria-se a roda para que os alunos pudessem contar suas próprias histórias. Desde o início procurei deixar bem claro que eles tinham liberdade para contar o que desejassem. E, aos comentários de "eu não sei nenhuma história", eu respondia que tudo poderia ser considerado história: contos tradicionais, fábulas, memórias de família, narrativas pessoais, contos de fada, histórias inventadas, filmes etc.

Um dos primeiros elementos que constatei ao iniciar a pesquisa foi que as crianças dificilmente contavam histórias de seus países de origem e preferiam, ao contrário, narrar contos de fada como Chapeuzinho Vermelho ou Cinderela, por exemplo. Compreendi que a demanda pela integração à nova realidade, fortemente encorajada pela escola uma das instituiçóes com papel mais proeminente na implementação das políticas do Estado $^{11}$ —, se refletia claramente na escolha das histórias. Porém, à medida que fomos estabelecendo um vínculo maior e que encontramos momentos de mais privacidade, em que as crianças podiam contar suas histórias apenas para mim, as referências ao país ou à cultura de origem começaram a aparecer. Assim, em pouco tempo ficava claro um dos desafios com os quais as crianças imigrantes têm de lidar na escola: como integrar-se à nova cultura (e à escola) mantendo viva a memória de onde partiram?

Ao longo da pesquisa, fui percebendo que, por meio das performances das histórias, esses conflitos eram expressos e negociados. A adoção do conceito de performance, aqui, como ferramenta analítica 
possibilita compreender a integração dessas crianças no contexto escolar por um prisma processual de aprendizagem que está ligado à agência criativa delas.

Podemos observar um claro exemplo desse esforço de integração na narrativa de Aminata, uma menina originaria do Senegal, que à época da pesquisa tinha 9 anos:

\section{Chapeuzinho Vermelho}

A Chapeuzinho Vermelho partiu para a floresta e viu um lobo. Ela levava uns biscoitos para sua avó. Quando ela partiu, ela viu um lobo. O logo partiu com a Chapeuzinho Vermelho. Ele disse: "Eu vou por lá e você vai por lá". Um dia, depois, o lobo partiu para a casa da avó da Chapeuzinho Vermelho. Ele bateu na porta da casa da avó. Ela sempre, Chapeuzinho Vermelho, colhia flores. O lobo chegou à casa e comeu a avó da Chapeuzinho Vermelho. Ela chega na casa de sua avó e ela náo tinha visto o lobo na cama. O lobo comeu a Chapeuzinho Vermelho e comeu todas as pessoas da floresta. A Chapeuzinho Vermelho entrou na casa de sua mãe. Depois, ela disse: "Toc, toc! Você tem grandes orelhas. Você tem um grande nariz. Você tem uma grande boca. Você tem grandes olhos". Ele diz: "É para te escutar". E o lobo come a Chapeuzinho Vermelho [tradução nossa] ${ }^{12}$.

Aminata tinha chegado à França havia pouco mais de quatro meses e, embora tivesse grande dificuldade na expressão escrita, já dominava bem o idioma na oralidade. Até mesmo a professora se surpreendeu quando Aminata começou a contar essa história, pois, além de usar o vocabulário francês corretamente, ela demonstrou grande habilidade na performance: levantou-se e posicionou-se em frente aos colegas para contar, modificou sua voz ao assumir a fala das personagens, atualizou as açóes por meio de gestos etc. Os principais elementos da história de Chapeuzinho Vermelho - que ela ouvira diversas vezes desde que chegou ao país - constavam de sua performance, porém 
dispostos em uma sequência diferente, não linear: o lobo come a menina, depois ela entra na casa. Ela entra na casa e depois bate à porta. O fim impactante, no entanto, foi preservado: Chapeuzinho Vermelho é devorada pelo lobo.

O nível de integração está representado aqui, em grande parte, pelo aprendizado não apenas do idioma, mas da cultura escolar e da cultura francesa em sentido amplo.

Embora esse processo de integração preveja uma série de enquadramentos e obediência a regras, as crianças não o recebem passivamente. Com as escolhas do que e como narram — por meio das performances - , podemos perceber claramente a agência desses pequenos narradores nesse processo.

Como estamos vendo, as crianças imigrantes deparam rapidamente, em todos os níveis de atividades que desenvolvem no novo país, das mais cotidianas às mais complexas, com o desafio da tradução. Se por um lado a língua francesa é imposta pelo Estado pela escola, por outro lado é esta que permite a comunicação entre as crianças recém-chegadas de diferentes países. Traduzir, nesse contexto, não se apresenta apenas como um processo de substituição, mas de compreensão, adaptação e, por que não, de criação de significados. Esse exercício constante exige aprendizagem. A habilidade, a destreza e o sucesso na tradução estão ligados, se adotarmos a perspectiva de Tim Ingold (2001), a uma "educação da atenção". Essa educação da atenção envolve um "conhecimento sensível” gerado por uma forma de aprendizagem ligada à sensibilização de todo o sistema perceptivo. Aqui podemos nos perguntar: como essa aprendizagem se manifesta nas performances narrativas dessas crianças de origens culturais tão distintas? Eu diria que por intermédio de estratégias verbais e dispositivos sonoro-corporais que combinam criativamente diferentes referências narrativas.

Podemos agora, finalmente, voltar à narrativa de Demba e Adul. Os meninos que me intrigaram com sua narrativa tinham, à época da pesquisa, 8 e 10 anos, respectivamente, eram muçulmanos e tinham chegado havia poucos meses à França. Embora oficialmente 
com 8 anos, Demba parecia ter pelo menos 12, e seu irmão, uns 14 ou 15. Eram rapazotes bonitos e ambos mais altos do que eu. Confessei meu estranhamento à professora da turma, que me explicou que muitas famílias imigrantes não dispóem de registros de nascimento de seus filhos e acabam por declará-los mais jovens, para que possam receber durante um período maior o auxílio governamental destinado às crianças em idade escolar. Esse auxílio, em muitos casos, garante a sobrevivência de toda a família. O desafio posto às crianças e aos jovens imigrantes, nesse caso, está diretamente relacionado a seus corpos: eles têm de assumir um papel que negava sua altura, sua voz, sua postura. Compreender o contexto escolar sob as lentes dos estudos da performance permite enxergar esses corpos, vozes e gestos em sua concretude, na relação com a instituição, com os pares, com os adultos, com o tempo/espaço da sala de aula.

Os meninos/rapazes eram falantes de peul e de créole e, apesar de seus esforços, tinham muita dificuldade (ou, visto de outra maneira, resistência) em se comunicar em francês. A princípio bastante avessos à troca de histórias que animava as crianças menores, eles eram seduzidos pelo aparato eletrônico que eu levava e sempre se voluntariavam para manipular a câmera fotográfica, filmar ou gravar as performances de seus colegas. Passadas algumas semanas do início do projeto, eles manifestaram o desejo de contar uma história, porém fizeram-no diferentemente das demais crianças, digitando a narrativa (esse pequeno texto que serve de epígrafe a este artigo) diretamente em meu notebook. Só depois é que, rindo muito, eles se dispuseram a narrá-la oralmente. Até então, eu nunca os havia escutado falar em seu idioma de origem, pois o uso de qualquer idioma que não seja o francês é desestimulado - e até mesmo censurado — na escola, já que a regra preconizada pelos textos oficiais implica que a língua francesa seja considerada simultaneamente objeto de estudo e meio de acesso aos saberes locais (CARRE; SABRIER, 2009).

Admito que durante a narrativa oral de Adul (pois foi ele quem tomou a palavra), tive dificuldade em entender as palavras, mas sua performance (gestos, expressividade facial e entonação da voz) fez-me compreender que se tratava da história de uma menina que era atacada 
por um lobo. Enfaticamente, a narrativa concluía-se com o nome da menina: Ratafia.

Quando fui transcrever a história, descobri que o créole falado pelos meninos possuía muitas afinidades com o português e que me era mais fácil "traduzi-la", em um primeiro momento, para o meu idioma materno. Logo ficou claro que esse foi também o motivo pelo qual Demba e Adul optaram em contar essa narrativa apenas para mim, e não para a professora e os demais colegas. Além de estrangeira, eu falava um idioma que eles identificavam como próximo ao seu. Este, como pude comprovar em outras situaçóes, era mais um desafio da experiência imigrante na escola: encontrar brechas no sistema para se fazer ouvir.

Para realizar minha tradução, portanto, eu tinha à minha disposição a narrativa escrita (que é citada na epígrafe) e a narrativa oral performatizada. Foi com base nesse conjunto de elementos que cheguei à versão que segue:

A história de uma menina que ia buscar lenha no mato. Ela olha um lobo e depois corre, chora, chora. Depois a menina morre. O papai da menina olha sua filha deitada no cháo. O papai chora, depois o lobo vem e fala não chora e come o papai da filha. Depois a mamãe da filha, o lobo vem e come a mamãe da menina. O lobo fala: como é seu nome? Ratafia.

Não é preciso uma comparação mais profunda para perceber que a história dos meninos se conecta com a história de Aminata (contada algumas semanas antes), no entanto não foi isso que me intrigou e posteriormente guiou minha análise. Ao contrário de Chapeuzinho Vermelho, a menina Ratafia era a única sobrevivente da fome voraz do lobo (embora também morra no início) e seu nome só foi pronunciado na última palavra da narrativa. Quem era, afinal, Ratafia?

Parti em busca de respostas e a primeira definição que encontrei foi a seguinte: " $f$. Licor aromático, em que entra aguarden- 
te, açúcar etc. Designação genérica de licores, doces e aromáticos. (Fr. ratafia)". Procurei achar alguma conexão, mas notei que esse caminho não estava sendo produtivo. Por que a menina teria o nome de um licor? Resolvi continuar a busca e encontrei outra definição mais significativa: "Palavra créole que pode ser originária da fórmula latina rata fiat, porque essa fórmula acompanhada de um brinde seria pronunciada após a conclusão de um negócio"13. Ou seja, Ratafia seria uma palavra em creóle (crioulo), proveniente do latim rata fiat, pronunciada quando algum negócio era concluído, significando "está feito". A palavra teria dado origem a ractifier, que significa ratificar em francês.

Dispondo destas pistas — elementos narrativos, contextuais e das informações etimológicas —, pudemos traçar algumas considerações:

1. Demba e Adul haviam me confiado uma história que, embora pudesse guardar semelhanças com um conto tradicional francês, apresentava uma trajetória totalmente distinta para a personagem protagonista: a criança sobrevive solitária ao massacre da família e do vilarejo. Lembro-me aqui da sentença de Claude Mesmin: "Qualquer pessoa, na escola, se encontra só em frente a uma enorme máquina que é, definitivamente, o Estado" (MESMIN, 1995, p. 16, tradução nossa);

2. Ao optarem por me contar uma história em créole, os meninos operaram uma forma de resistência, já que constantemente, no âmbito da sala de aula, eram repreendidos quando pegos falando nesse idioma entre si. Novamente recorro a Mesmin: "A língua não é somente um conteúdo, é igualmente um continente, ela não se limita a um conjunto de palavras, mas reenvia à associação de ideias" (MESMIN, 1995, p. 37). A performance em créole, portanto, aciona não apenas palavras, mas sons e sentidos que reconectam os meninos com sua cultura;

3. A mediação tecnológica mostrou-se um elemento fundamental para a ativação da performance oral. Foi somente com a 
possibilidade de escreverem sua história no computador que os meninos se sentiram confiantes para, no momento seguinte, darem corpo e voz à narrativa de Ratafia. O olhar acurado sobre esse processo proporciona um acesso privilegiado às concepçóes, às interpretaçóes, aos sonhos e às reflexóes que as crianças e jovens têm a respeito de sua realidade;

4. Ao assumirem a responsabilidade de contar uma história, Demba e Adul assumiam-se, também, como performers. Adoto aqui a perspectiva de Dell Hymes (1975), que define a performance como um comportamento cultural por meio do qual uma pessoa assume a responsabilidade de contar, demonstrando competência comunicativa diante de uma audiência. O/a contador/a assume, dessa forma, a autoridade da narração. Essa autoridade, penso, permitia aos meninos se colocarem como agentes ativos no difícil processo de integração à nova realidade.

A prática da escuta das crianças com base em seus referenciais de origem, no entanto, não cabe necessariamente nos protocolos escolares convencionais. Pelo contrário, a diversidade étnico-cultural é frequentemente vivida na escola como uma dificuldade, um problema ou mesmo um fardo. Como apontam Santiago, Akkari e Marques: "Muitas vezes há também uma transferência entre os discursos dos atores escolares sobre a diversidade escolar indesejada e o fracasso escolar, a violência ou a inadaptaçáo". Segundo os autores, o problema é que a escola contemporânea, tornada obrigatória na segunda metade do século XIX, foi formada com base em uma nação, uma bandeira e um idioma - todos no singular. Nesse cenário, como seria possível garantir o espaço/tempo para a expressáo da diversidade dos alunos? Antes de formular qualquer resposta, é fundamental relacionarmos a construção social da diversidade com a desigualdade. Como constata o Colectivo AMANI (2009, p. 21), grupo espanhol que desenvolve desde 1992 uma proposta de educação intercultural, com enfoque socioafetivo: "Las relaciones de poder jerarquizadas suponen una valoración negativa de la diversidad, asociando normalmente diversidad a problema, conflicto". 
$\mathrm{Na}$ França, frequentemente deparamos com estatísticas que insistem em reforçar que os imigrantes e as crianças/os jovens de baixa renda, habitantes de bairros populares, são os principais atingidos pelo fracasso escolar. Tobie Nathan, em entrevista a Mesmin (1995, p. 20, tradução nossa), denuncia:

Cada membro da instituição escolar tenta minimizar o escândalo absoluto de que as crianças imigrantes são, em sua maioria, consideradas em fracasso escolar. Se a escola tem realmente a missão de "encher de bons conhecimentos" todas as crianças, por que ela não consegue com as crianças imigrantes?

Poderíamos arriscar uma resposta: talvez porque essas crianças já tenham outros conhecimentos (desprezados) que entram em conflito com aqueles que são ensinados na escola.

Refletindo sobre esse dilema, Santiago, Akkari e Marques (2013, p. 79) concluem que a pressão para cumprir padróes externos compromete a capacidade das escolas de responder à diversidade cultural dos alunos. Surge então outra pergunta: se a escola é pensada no singular, como poderia acolher a pluralidade de corpos, vozes e saberes de seus alunos?

De acordo com Lepe et al. (2012, p. 33), as consequências pedagógicas mais evidentes na escola em relação à diversidade cultural têm sido, em termos gerais:

1. O olhar folclórico sobre as diferenças — a diversidade é trabalhada nas efemérides, normalmente de forma estereotipada, na chave turística ou exótica;

2. O olhar compensador, que atua na chave da superação de déficits por parte dos sujeitos;

3. O mito da igualdade de trato, assentado na relação radical da diferença entre todos os indivíduos, sem reconhecer a existência de desigualdades nas posiçóes sociais. 
Procurando escapar dessas armadilhas, minha proposta de ação com as crianças imigrantes pautou-se na escuta ativa, no respeito, na abertura às possibilidades de relação e troca e na constante avaliação compartilhada do processo. Acredito que, como Décourte e Raynaud, os contos se prestam a diversas instâncias de interação na escola e que sua presença em uma turma de jovens pertencentes a horizontes culturais diferentes abre um espaço de variaçóes que se afasta dos exotismos e institui o plural: "Lugar de encontro de culturas, o conto permite ver o idêntico e o diferente" (DÉCOURTE; RAYNAUD, 1999, p. 201 ${ }^{14}$.

O processo de aprendizagem de Aminata, Demba e Adul, assim como o de muitas outras crianças imigrantes na mesma situação, não pode ser pensado apenas em relação ao nível de aquisição da língua francesa e de capacidade de tradução, mas num sentido mais amplo, em relação a todos os "conhecimentos sensíveis" (INGOLD, 2001) adquiridos sobre distintos âmbitos, como as regras da escola, os tipos de estrutura narrativa, as características do público ouvinte etc.

Há inúmeros desafios a serem vencidos pelas crianças imigrantes, como também há muitos desafios para quem se dispóe a trabalhar a favor da diversidade cultural em sala de aula:

Uma educação que seja culturalmente sensível não é uma forma prescrita ou um conjunto de competências adquiridas rapidamente, é um processo contínuo que envolve a tomada de riscos e uma abertura à aprendizagem pela alteridade (SLLETER; CORNBLETH, 2011 apud SANTIAGO; AKKARI; MARQUES, 2013, p. 93).

Ao encarar a aprendizagem pela alteridade, assumimos os inúmeros ruídos de comunicação, a incompletude da compreensão, a ausência de respostas precisas. Sob as lentes da performance, porém, esses ruídos, essas incompletudes e essas ausências ganham voz, cor, corpo, movimento. No fundo é esse conjunto instável que dá sentido e que permite transformar as experiências dos sujeitos que se encontram na escola.

Ratafia sobreviveu ao lobo. Os meninos riem. "Está feito"! Eles podem contar sua história. 


\section{REFERÊNCIAS}

ALDERSON, P. As crianças como pesquisadoras: os efeitos dos direitos de participação sobre a metodologia de pesquisa. Educação e Sociedade, Campinas, v. 26, n. 91, p. 419-442, 2005.

BEGNAMI, P.S. Crianças: os sujeitos das pesquisas antropológicas. Revista UNAR, Araras, v. 4, n. 1, p. 2-12, 2010.

CARRE, D.; SABRIER, C. Travaux d'écriture: quels enjeux pour des ENAF? Cahiers Pédagogiques, n. 473. Disponível em: <http://www.cahierspedagogiques.com/Travaux-d-ecriture-quels-enjeux-pour-des-ENAF>. Acesso em: 13 maio 2014.

CASNAV. Les élèves nouvellement arrivés en France sans maittrise suffisante de la langue française ou des apprentissages. Enquête statistique Premier degré Année scolaire 2009-2010. Disponível em: <http://18b-gouttedor.scola.ac-paris.fr/ IMG/pdf/statistiques CLIN 09- 10.pdf >. Acesso em: 06 out. 2014.

COHN, C. Antropologia da criança. Rio de Janeiro: Jorge Zahar, 2005.

COLECTIVO AMANI. Educación Intercultural: análisis y resolución de conflitos. Madri: Catarata, 2009.

DÉCOURTE, N.; RAYNAUD, M. Contes et diversités des cultures: le jeu du même et de l'autre. Lyon: CRDP de l'Académie de Lyon, 1999.

GAUTIER, M. L'éclectisme de la classe d'initiation (CL.IN.) Mémoire pour le Concours de recrutement: Professeur des écoles. IUFM de Bourgogne, 2005/2006.

HALL, S. Da Diáspora: identidades e mediações culturais. Belo Horizonte: Ed. da UFMG, 2003.

HARTMANN, L. Equilibristas, viajantes, princesas e poetas: performances orais e escritas de crianças narradoras. Boitatá - Revista do GT de Literatura Oral e Popular da ANPOLL. Londrina, n. 20, p. 48-67, 2015.

. Interfaces entre a Pedagogia do Teatro e os Estudos da Performance. Educação, Santa Maria, v. 39, n. 3, p. 515-528, set./dez. 2014.

HYMES, D. Breakthrough into Performance. In: BEN-AMOS, D.; GOLDSTEIN, K.S. (orgs.). Folklore: Performance and Communication. Paris: Mouton, 1975.

ICLE, G. Da performance na educação: perspectiva para a pesquisa e a prática. In: PEREIRA, M.A. (org.). Performance e Educação: (des)territorializaçôes pedagógicas. Santa Maria: Ed. da UFSM, 2013. p. 9-22. 
INGOLD, T. From the transmission of representations to the education of attention. In: WHITEHOUSE, H. (ed.). The Debated Mind: evolutionary psychology versus ethnography. Oxford: Berg, 2001. p. 113-153.

LEPE, E.M.; TORRICO, M.G.-C.; DOMÍNGUEZ, I.A.; LÓPEZ, R.C.; ALFAYA, E.G.; ORDAZ, R.G.; TOMÁS, J.M. Educación intercultural y comunidades de aprendizage. Madri: Catarata, 2012.

MESMIN, C. Psychothérapie des enfants de migrants. Paris: La Pensée Sauvage, 1995.

MONTANDON, C.; LONGCHAMP, P. Você disse autonomia? Uma breve percepção da experiência das crianças. Perspectiva, Florianópolis, v. 25, n. 1, p. 105-126, 2007.

NATHAN, T. L'influence qui guérit. Paris: Odile Jacob, 2001.

SANTIAGO, M.C.; AKKARI, A.; MARQUES, L.P. Educação Intercultural: desafios e possibilidades. Petrópolis: Vozes, 2013.

SARMENTO, M.J. Imaginário e culturas da infância. Cadernos de Educação, Pelotas, v. 12, n. 21, p. 51-69, 2003.

SCHECHNER, R. Performance Theory. Nova York e Londres: Routledge, 1988.

. O que pode a performance na educação. Educação \& Realidade, Porto Alegre, v. 35, n. 2, p. 23-35, 2010.

VASSEUR, M-T. En CLIN, l'apprentissage du français passe par la socialisation en français. Linx, v. 49, p. 125-140, 2003.

\section{NOTAS}

1. No intuito de preservar as identidades das crianças, todos os nomes utilizados no artigo são fictícios, porém sua criação procurou respeitar as origens étnicas de cada uma.

2. Pesquisa realizada com bolsa de Estágio Sênior da Coordenação de Aperfeiçoamento de Pessoal de Nível Superior (CAPES), na Université Paris Ouest Nanterre-La Défense, sob supervisão da Professora Idelette Muzart Fonseca dos Santos.

3. Embora atualmente denominadas pela sigla UPE2A (Unité Pédagogique pour Élèves Allophones Arrivants), essas turmas continuam a ser chamadas de CLIN pela comunidade escolar. 
4. De acordo com pesquisa realizada pela CASNAV (Centre Académique pour la Scolarisation des Enfants Allophones Nouvellement Arrivés et des Enfants du Voyage), em 2009-2010, havia 57 CLIN em Paris.

5. Ver Boletins Oficiais do Ministério nacional da Educação, n. 141, de 2 de outubro de 2012, e n. ${ }^{o} 102$, de 25 de abril de 2002, entre outros. Disponíveis em: <http://www. education.gouv.fr/pid285/bulletin_officiel.html>.

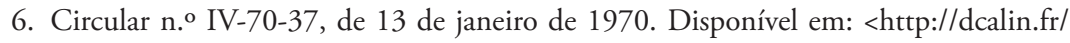
textoff/clin_1970.html>. Acesso em: 15 maio 2016.

7. Texto original: "Si la maîtrise de la langue française dans ses usages oraux et écrits est une priorité, l'apprentissage du vivre ensemble constitue une autre finalité essentielle de l'école. Ainsi, l'intégration en milieu ordinaire constitue non seulement un principe ou un objectif mais aussi la modalité principale de scolarisation".

8. Texto original: "Lécole réunit des individus qui sont séparés de leur monde, de leur milieu, pour les metre tous ensemble et les agglutiner de manière arbitraires — simplement parce qu'ils habitent le même quartier, par exemple — alors qu'ils ne sont pas reliés entre eux par les mêmes liens culturels et sociaux".

9. No novo ano escolar, que se iniciou em setembro de 2014, a professora Noelle transferiuse para uma escola, localizada no $10 .^{\circ}$ arrondissement, e convidou-me a desenvolver o mesmo projeto em sua nova turma da CLIN, o que fiz até janeiro de 2015.

10.Eu já havia experimentado essa estratégia metodológica em pesquisa realizada em uma escola pública de Sobradinho, Distrito Federal, com resultados bastantes férteis, alguns meses antes de iniciar o pós-doutorado. Ver HARTMANN (2015).

11.O etnopsiquiatra Tobie Nathan aponta a falta de respeito às culturas de origem dos imigrantes em instituiçóes como o sistema médico-hospitalar e a escola, que, segundo ele, são os dois lugares institucionais nos quais se percebe o imigrante como um "humano universal", e não como um ser de cultura (NATHAN, 2001, p. 191).

12.La Petite Chaperon Rouge elle est partie a la forêt et elle a vu um loup. Elle a rammené une gallette pour sa grandmère. Quand elle est partie elle a vu un loup. Le loup il est parti avec la Petite Chaperon Rouge. Il dit: "Moi, je part par là, et toi, tu vas partir par là". Un jour, après, le loup a parti dans la maison de la grandmère de la Petite Chaperon Rouge. Il a frappé la porte de la maison de la grandmère. Elle toujour, le Petite Chaperon Rouge, elle prends de fleurs. Le loup est arrivé a la maison et a mangé la grandmère de la Petite Chaperon Rouge. Elle arrive chez sa grandmère et elle n'a pas vu le loup dans le lit. Le loup a mangé la Petite Chaperon Rouge et il a mangé tout le gens de la forêt. La Petite Chaperon Rouge elle est rentré a la maison de sa grandmère. Après, elle a dit: "Toc toc! Tu as de grandes oreilles. Tu as un grand nez. Tu as une grande bouche. Tu as des grand yeux". Il dit: "S'est bien pour écouter". Il le loup a mangé la Petite Chaperon Rouge. 
13. Tradução nossa. Texto original: "Mot créole peut être issu de la formule lat. rata fiat (conventio) parce que cette formule accompagnée d'un toast se serait prononcée à l'occasion d'un marché conclu". Disponível em: <http://www.cnrtl.fr/definition/ratafia>. Acesso em: 03 maio 2016.

14. Tradução nossa. Texto original: "Lieu de rencontre des cultures, le conte donne à voir l'identique et le différent".

Recebido em 04 de outubro de 2016.

Aprovado em 23 de fevereiro de 2017. 